\title{
Disinfection of Sewage from Municipal Wastewater Treatment Plants of Lviv
}

\author{
Olena Popovych, Nataliya Vronska, Ivan Tymchuk \\ Department of Ecology and Sustainable Environmental Management Lviv Polytechnic National University, \\ UKRAINE, Lviv, Stepan Bandera street, 12, E-mail: lpolenaeko@yahoo.com
}

\begin{abstract}
Devoted to the problem of sewage treatment by ultraviolet radiation. This method can clear the water from microbiological contamination and thereby improve water quality.
\end{abstract}

Keywords - water treatment, disinfection, UV-radiation, microflora, sewage.

\section{Introduction}

The reservoirs contain a large number of microorganisms: clean reservoirs - tens and hundreds of thousands of microorganisms in $1 \mathrm{~m}^{3}$, contaminated - millions and billions of microorganisms in $1 \mathrm{~m}^{3}$. Their number depends on the season (in summer, the number of microscopic algae and cyanobacteria, which can cause water blooms, is very high in reservoirs). Among them there are species that constantly inhabit the reservoirs, as well as those that fall there with sediments, sewage, and so on. Microflora is represented by various groups of microorganisms - bacteria, microscopic mushrooms, actinomycetes, algae, protozoa are found [1].

The most simple, cheap and widely used method of decontaminating water is chlorination. In Ukraine chlorination of water began to be used since 1908. The degree of decontamination depends mainly on the concentration of active chlorine, contact time, $\mathrm{pH}$ value and water temperature. The main disinfectant is active chlorine. However, despite the effectiveness of pathogenic bacteria, chlorination does not provide epidemic safety for viruses. Also, the negative property of such a method is the formation of organochlorine compounds and chloramines. [2].

One of the alternatives to chlorination of water is the decontamination of ozone. Ozone is a universal reagent, because it can be used for decontamination, discoloration, deodorization of water, for removal of iron and manganese. This method also has its disadvantages: by-products of ozonation - aldehydes (formaldehyde) and ketones, as well as the complexity and high cost of ozone production and the need for constant monitoring of ozone production [3].

\section{Main part}

One of the most effective methods of disinfecting water is ultraviolet irradiation. The effect of UV radiation on different types of microorganisms has the same nature, the main mechanism of which is the destruction of DNA and RNA structures in microorganisms under the influence of radiation in the region of $220-280 \mathrm{~nm}$, the maximum bactericidal action takes place at a wavelength of $260 \mathrm{~nm}$ [4].

Ultraviolet radiation is instantaneous, at the same time, the radiation does not add water to the residual bactericidal properties, as well as the smell and taste. Water treatment with UV radiation does not lead to the formation of harmful by-products of chemical compounds [5].

The efficiency of sewage treatment from bacterial contamination by UV-radiation was studied for municipal sewage treatment plant № 2 of Lviv.

The sanitary-epidemiological assessment of the quality of water was determined by the indicator of the total microbial number (TMN) - the total number of bacteria in $1 \mathrm{~cm}^{3}$ of the water being studied. TMN estimates the total contamination of sewage by microorganisms [6]. The essence of the method is to determine the total number of microorganisms that can grow on meatpeptide agar with temperature of $37 \pm 0.5^{\circ} \mathrm{C}$ for $24 \pm 2$ hours per $1 \mathrm{~cm}^{3}$ of water, followed by the account of the colonies grown in this medium. 
Experiments were carried out at different time (from $5 \mathrm{~s}$ to $20 \mathrm{~s}$ ) and for different thickness of the layer of the investigated liquid (from $25 \mathrm{~mm}$ to $45 \mathrm{~mm}$ ).

To study the influence of ultraviolet light on the decontamination of microorganisms, a UV installation of the tray type, shown in Fig. 1

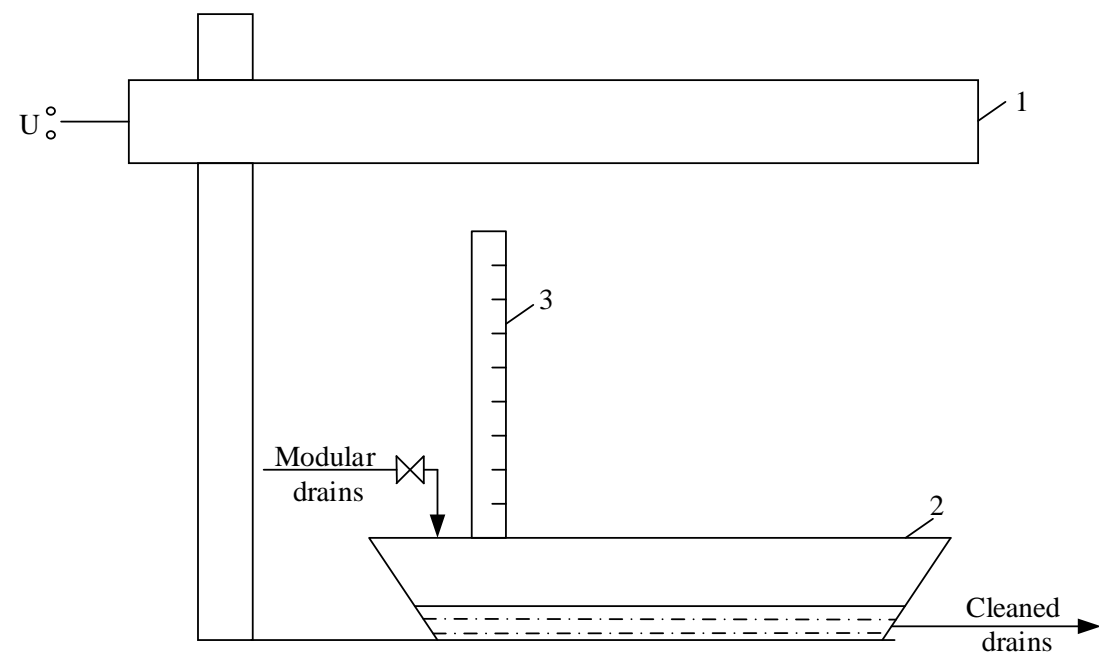

Fig. 1. Scheme of an experimental installation for the process of water disinfection:

- ultraviolet lamp, 2 - liquid tray, 3 - way rack

The research results are presented in Fig. 2

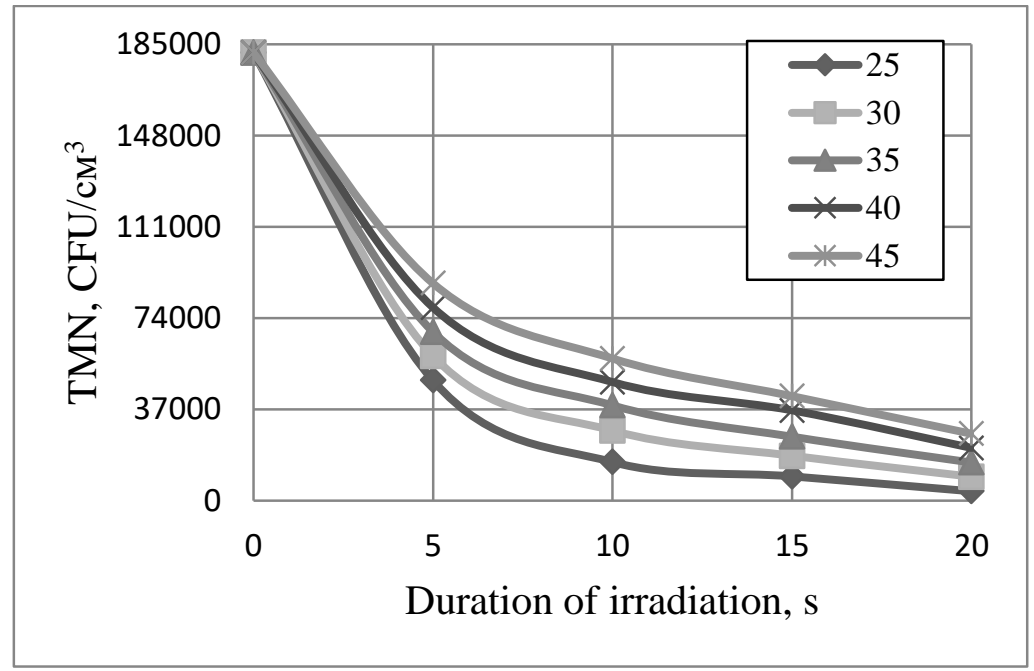

Fig. 2. Dependence of TMN on the duration of irradiation UV-radiation and different thickness of the drainage layer $(\mathrm{mm})$

Studies have shown that with irradiation of $20 \mathrm{~s}$ and a thickness of $25 \mathrm{~mm}$ water, TMN is $3757 \mathrm{CFU} / \mathrm{cm}^{3}$, and the duration of irradiation of 20 seconds and the thickness of the water layer of $45 \mathrm{~mm}$ was $27097 \mathrm{CFU} / \mathrm{cm}^{3}$.

The degree of efficiency of the process of disinfection of wastewater is the degree of purification, which is determined by the formula:

$$
N_{m}=\frac{N M_{0}-N M_{1}}{N \mathrm{M}_{0}}=1-\frac{N \mathrm{M}_{1}}{N \mathrm{M}_{0}}
$$

where $\mathrm{NM}_{1}$ - number of microorganisms remaining in water after the action of $\mathrm{UV}, \mathrm{CFU} / \mathrm{cm}^{3}$; $\mathrm{NM}_{0}$ - number of microorganisms that were in water before the start of its radiation, $\mathrm{CFU} / \mathrm{cm}^{3}$. 
Data shown in Fig. 2, were processed according to the dependence (1). The obtained results are presented in Fig. 3

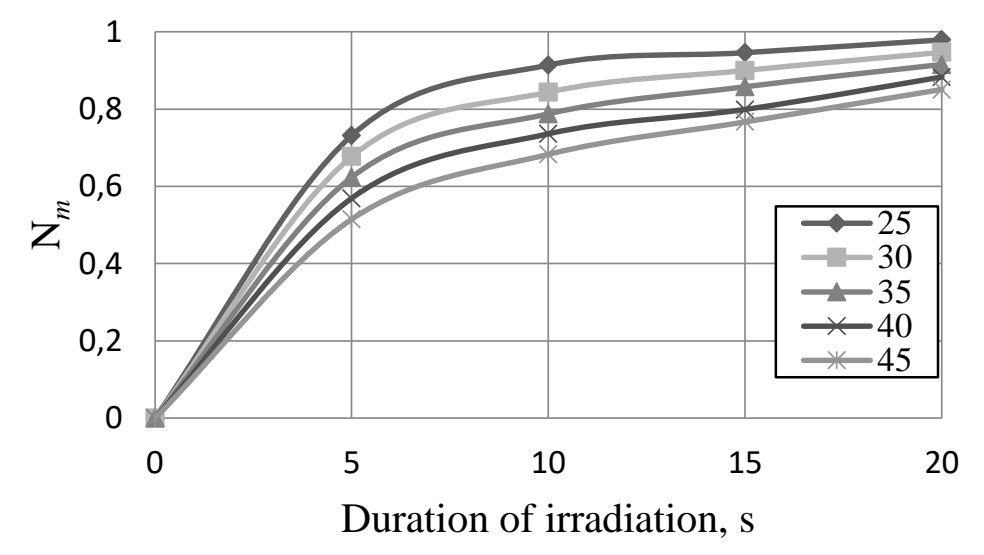

Fig. 3. Dependence of the degree of purification on the duration of irradiation for sewage in municipal sewage treatment plant №2 for different thickness of the liquid layer (mm)

The above data indicate that the degree of purification for municipal sewage treatment plant №2 sewage in the limits of a layer of liquid from $25 \mathrm{~mm}$ to $45 \mathrm{~mm}$ at $20 \mathrm{~s}$ with radiation decreased from 0.9793 to 0.8508 .

\section{Conclusion}

Investigation process disinfection of water using UV-radiation from municipal water treatment plant №2 of Lviv showed that under the condition of $20 \mathrm{c}$ irradiation and thickness of the water layer $25 \mathrm{~mm}$, the TMN is $3757 \mathrm{CFU} / \mathrm{cm}^{3}$, while the duration of radiation is 20 seconds and the thickness of the water layer $45 \mathrm{~mm}$, this value amounted to $27097 \mathrm{CFU} / \mathrm{cm}^{3}$. Under the condition of $20 \mathrm{~s}$ with irradiation and thickness of the water layer of $25 \mathrm{~mm}$, UV treatment allowed to reduce the level of the MI by 48 times, while the irradiation time was $20 \mathrm{~s}$ and the thickness of the water layer was $45 \mathrm{~mm}-7$ times. The application of this method is effective and allows the implementation of this process to disinfection wastewater at the sewage treatment facilities of the city of Lviv.

\section{References}

[1] L. Rizzo et al., "Urban wastewater treatment plants as hotspots for antibiotic resistant bacteria and genes spread into the environment: A review", Science of The Total Environment, vol. 447, pp. 345-360, 2013.

[2] S.Jiménez et al., "State of the art of produced water treatment ", Chemosphere, vol. 192, pp. 186-208, 2018.

[3] N.F.Gray, "Pathogens and Their Removal" in Water Technology (Third Edition). Oxford: Butterworth-Heinemann, 2010, pp-360-400.

[4] T. Koutchma, "UV Disinfection of Air, Water, and Surfaces" in Sensory Food Plant Safety. London: Academic Press, 2014, pp-15-30.

[5] O-Mi Lee et al., "A comparative study of disinfection efficiency and regrowth control of microorganism in secondary wastewater effluent using UV, ozone, and ionizing irradiation process", Journal of Hazardous Materials, vol. 295, pp. 201-208, 2015.

[6] C.P.Gerba, M.Kitajima and B.Iker, "Viral presence in waste water and sewage and control methods" in Viruses in Food and Water. Philadelphia: Woodhead Publishing, 2013, pp-239315. 